Walker, Nathan ORCID:

https://orcid.org/0000-0001-8419-9018 (2014) Permutation and Randomness in the Action Score Generator. Journal of writing in creative practice, 7 (1). pp. 213-221.

Downloaded from: http://ray.yorksj.ac.uk/id/eprint/591/

The version presented here may differ from the published version or version of record. If you intend to cite from the work you are advised to consult the publisher's version: http://dx.doi.org/10.1386/jwcp.7.1.213_1

Research at York St John (RaY) is an institutional repository. It supports the principles of open access by making the research outputs of the University available in digital form. Copyright of the items stored in RaY reside with the authors and/or other copyright owners. Users may access full text items free of charge, and may download a copy for private study or non-commercial research. For further reuse terms, see licence terms governing individual outputs. Institutional Repository Policy Statement

\title{
RaY
}

Research at the University of York St John

For more information please contact RaY at ray@yorksj.ac.uk 


\section{Permutation \& Randomness in the Action Score Generator}

\section{Nathan Walker}

The following is the authors accepted manuscript for an article published in Journal of Writing in Creative Practice.

Suggested citation: Walker, N. (2014), 'Permutation and randomness in the Action Score Generator', Journal of Writing in Creative Practice 7: 1, pp. 213-221, doi: 10.1386/jwcp.7.1.213_1

Abstract: This article discusses the Action Score Generator (ASG), an online writing machine that randomly arranges words into six-word-length performance scores. The generator belongs to a lineage of language-based artworks and practices that relinquish authorial control to the viewer. Exploring the methods of Event Scores developed by George Brecht the ASG is a website that distributes an infinite number of scores as both instructions and poetry. This is articulated in relation to Christopher Strachey's 'Love Letter Generator' and other permutational and computational writing programmes that use randomness and code to produce writing in modular forms.

Keywords: Event Score, George Brecht, computer generator, Christopher Strachey, e-poetry, Nathan Walker

Knife, Teeth, Towel, Rope, Glue, Carabiner, Chair, Microphone, Cone, Whistle, Glass, Book, Rope, Door, Hammer, Nails, Underwear, T-Shirt, Postcard, Dust, Slate, Bricks, Rocks, Wood, Shoes, Bags, Picture, Pencils, Flag, Dirt, Bucket, Water, Coins, Stick, Shirt, Nail, Tongue, Hair, Arm, Shoe, Tape, Lemon, Comb, Spit, Slates, Turps, Polythene, Photo, Photos, Branch, Branches, Plant, Plants, Plank, Planks, Roses, Sand, Buckets, Typewriter, String, Bag, Bags, Strings, Object, Objects, Torch, Trousers, Jacket, Coat, Flowers, Placard, Placards, Curtain, Curtains, Sock, Socks, Scissors, Braces, Whiskey, Soap, Sheet, Swan, Paper, Newspaper, Newspapers, Ribbon, Ribbons, Chairs, Stool, Table, Weight, Glitter, Sponge, Sponges, Belt, Pen, Bells, Tambourine, Chimes, Drawing, Haunt, Concrete.

These objects are a list of materials that I have used in performances. They are not arbitrary but specific, belonging to an archive of practice in action art from the last eight years. They are indexical of specific task-based actions and symbolic of a kind of object-vocabulary present within my performance practice. Like the other words in the Action Score Generator (ASG), they are prewritten source words that, together, create instructions, descriptions and poems. As a writing programme the structure of the texts in the ASG are fixed in word-length but their appearance and layout on the page, shifts depending on the size of the 
Nathan Walker 'Permutation and Randomness in the Action Score Generator' 2014 words chosen by the generators code. Building upon a practice that moves between live performance and performance for the page or screen, this performing webpage is informed by concrete and visual poetry.

I have been influenced by artists using language as art and, for me, this begins with concrete poetry and extends to the works developed by George Brecht with his Event Scores. This practice became more explicitly explored in the conceptual practices of the 1960s and 1970s, and these lineages run in parallel to one another. The scores of the ASG are considered to be akin to Fluxus Event Scores, which in Emmett Williams' words were 'born out of experiments in concrete poetry as it "got off the page"' (Dezeuze 2002: 79). Getting off the page and beyond the screen is explored by considering different ways to interpret, read and realize these text-scores as art.

The ASG is accessed as a website and has been constructed as a simple piece of HTML, CSS and JavaScript that can be viewed across browsers and devices making it available as a portable reading experience. This also builds upon a key concern of Fluxus artists to disseminate and disperse material. For George Brecht '... the issue of distribution was a concern... as early as 1959 , when he asked: "shouldn't scores be simply published in the newspaper, or available on printed cards or sheets of paper, to be send to anyone"' (Dezeuze 2002: 79). That the material is concise enough to be distributed easily is suitable for contemporary modes of communication that have appeared in our increasingly digital lives. It is easy to see that Event Scores could exist as part of a 120character-long twitter feed which is, co-incidentally, the same amount of characters that are statistically produced on the back of a postcard.

My writing practice has almost always engaged with language-games, anagrams, concrete poetry and the physical re-arrangement of words as things and also belongs to an extended practice of working with performances as collage and collage as performance. It is no surprise to find that I am drawn to digital writing practices that enable machines to perform these re-arrangement functions more efficiently and rigorously than my mind or body.

I originally imagined that these texts could be read aloud as poetry, however, as Liz Kotz states 'Event scores... were rarely read aloud - the linguistic performativity they propose is closer to that of the iterability of the sign than to that of an overtly oral (and more conventionally literary) performance poetics' (2001: 106). The repeatability inherent in Event Scores, in both form and content, realization and conceptualization, is present within the ASG through the shifting processes of repeating structures, words and continual transformations. Kotz goes further saying that,

Rather than pulverizing language into sonorous fragments... scores focus on the instructions themselves as poetic material. This alternate poetics, of deeply prosaic everyday statements, comprised of short, simple, vernacular words presented in the quasi-instrumental forms of lists and instructions, emerged in the postwar era as a countermodel to the earlier avant-garde practices of asyntacticality, musicality, and semiotic disruption. Yet this poetics by no means represents a simple departure from or rejection of collage aesthetics, but... a complex transformation of its semiotic engagement, one that pursues the logic of the fragment to unprecedented levels of isolation, focus, and reduction. (Kotz 2001: 106) 
The ASG is a website that functions as a text generator using the 'logic of the fragment' (Kotz 2001: 106) to arrange scores for performance. Text is produced via a JavaScript code that is initiated by loading the site. When a user visits the site, the computer parses the code and produces what is called a JavaScript 'event'. This event begins a timed generation of texts that automatically appear on-screen for the user to view. In this sense there is no directly interactive function for the user, they become viewers of randomly written scores that exist in the form and development of Brecht's Event Scores. Indeed Brecht's first one-person exhibition in New York at Reuben Gallery 1959 was titled 'Towards Events: An Arrangement', which provides a useful way of thinking about the ASG. In the press release of Towards Events Brecht declares that the exhibition 'be enjoyed as an unfolding experience' (Robinson 2009: 88) and the same is true in the ASG. The constant unfolding, shifting and shuffling of these texts allow us to see them as arrangements towards an event.

Julia Robinson's historical overview of the event score explains that scores were 'indeterminate propositions: realizable equally as an object, a performance, or even a thought. Simply to read an Event score and reflect upon it without acting already constitutes an adequate realisation' (2009: 105). Which is echoed in text-artist Lawrence Weiner's famous statement: 'The artist may construct the work. The work may be fabrication. The work need not to be built' (in Robinson 2009: 105). Weiner's use of modular forms of writing were influenced by the work of George Brecht. The small, simple and poetic texts in the ASG are not only instructions but ideas; they offer a linguistic proposition that asks the viewer to interpret the work and relinquish authorial control from the creator. Event Scores are specific, concise, and often reduced to the shortest form possible to communicate the idea. Their graphic depiction on cards or reprinted in newspapers and magazines behave as modular segments. Although they are visually basic they are typographically specific so that '[t]he relationship between spatially arranged words are not fixed... but are open and flexible and subject to continual redefinition [during the process of reception]' (Schaffner 2010: 180).

The ASG continually redefines its possible readings by working with what Brecht calls the 'concept of strict randomness' (Robinson 2009: 83) within the framework of a digital writing machine. The continual redefinition and resampling of the index of source words here reflect the systematic permutations of works like Emmett Williams' 'Cellar Song for Five Voices', which reorders a sentence of fifteen word-length into each possible combination. An anagrammatic game, Cellar Song follows a logical and methodical system of rearranging the sentence:

Somewhere bluebirds are flying high in the sky, in the cellar even blackbirds are extinct. Somewhere bluebirds are flying high in the sky, even blackbirds are extinct in the cellar. Somewhere bluebirds are flying in the cellar high in the sky, even black birds are extinct. Somewhere bluebirds are flying in the cellar even blackbirds are extinct, high in the sky. 
This process of working with ready-made materials in performance, and in the generator, deals with language in the way one might deal with cards; as a methodology of fragmentation, collage and arrangement that are employed in many concrete and Fluxus poetic practices. In John Cage's words 'Making something out of a store of raw materials' (Dezeuze 2002: 83). The store of raw materials in the ASG are categorized as variables in the JavaScript code. Whilst the texts that are generated are random and automatic their structure is restricted in length and by their position in the string of the text. Each text uses any combination of single words within the variable code text-nodes, one to six, and so the content of the text follows a strict pattern of:
1. Object
2. Preposition
3. Thing
4. Verb
5. Preposition
6. Place

Each text is bookended by the 'object' (1) and the 'place' (6), the four central words indicate what happens but the beginning and end of each text supply the content of the task, its contextual data. This harnessing of systematic indeterminacy in the ASG begins with George Brecht's Event Scores and moves to, for example, Merce Cunningham's use of the computer programme 'LifeForms'. LifeForms can produce randomly generated movements that, like the linguistic propositions in this generator, do not always go together. For Cunningham and for me the poetics of the disjunctive and the awkward combinations of fitting and not fitting are where the poetics of the work lie.

Notably, the first random text computer generator was Christopher Strachey's 'Love Letter Generator' (1952), an extraordinary computer program that generated letters through a combinatorial system. The generator, as Noah Wardrip-Fruin has argued is the first known experiment in digital literature and 'perhaps the first digital art of any kind' (2011: 303). The program, developed for the Manchester Mark I at the University of Manchester, used two kinds of sentence permutations as outlined by Strachey:

The first is 'My-(adj.)-(noun)-(adv.)-(verb) your-(adj.)-(noun).' There are a list of appropriate adjectives, nouns, adverbs, and verbs from which the blanks are filled in at random. There is also a further random choice as to whether or not the adjectives and adverb are included at all. The second type is simply 'You are my-(adj.)-(noun),' and in this case the adjective is always present. (Strachey in Wardrip-Fruin 2011: 308)

Using vocabulary based on the Roget's Thesaurus, the generator selects words from each category of adjectives, nouns, adverbs, verbs with a choice of adjectives at the beginning and the end of the letter. In this respect, like the ASG there is a structural framework that 'fills in the blanks' through random selection process. Using small units of data, Strachey's generator produces love 
Nathan Walker 'Permutation and Randomness in the Action Score Generator' 2014 letters that are formed randomly by the computer. This is reflected in the unusual combinations of words in the sentences of the surface letters that are produced by the machine. As Wardrip-Fruin comments '[t]he letters preserved by Strachey are not texts that anyone would write...inhuman feeling comes from the mismatched awkwardness of [the] declarations' (2011: 307). This awkwardness is what categorizes my interest in permutational works. Anna Katharina Schaffner discusses another random machine-generated poem by Theo Lutz under the instruction of Max Bense in 1959. Here the computer programmes used similar rules of recombination and reorganization on Franz Kafka's The Castle. Schaffner (2010) states that 'because pragmatic selection restrictions are violated, syntactic compatibility clashes contrasts starkly with semantic incompatibility. However, it is precisely this incongruity, the surprise moment and the bizarre imagery which constitute the texts poetic appeal' (2010: 186). The incompatibility of some of the texts produced by the ASG is what makes these texts so intriguing. They function and they do not function, they shift between logical and possible instructions and instructions that, like Brecht's Scores and Strachey's letters, are extremely open to interpretation.

In the ASG modular form is both a process of working with random word sequences and the final product of six-word-length texts that continually alter, shift and mutate. Schaffner says that these 'permutational works are still a viable sub-genre in digital poetry' (2010: 186). This sub-genre may include Nick Montfort's 'Taroko Gorge' (2009) ${ }^{1}$ which has been processed and rewritten (and redistributed) by a number of contemporary digital poets including J. R. Carpenter, Leonardo Flores and Maria Engberg. Interestingly the events in permutational digital works are events that we view, not that we participate or interact with other than loading the webpage. As Anna Dezeuze asserts '[w]ith this shift to perceptual activities, the event score becomes as much an invitation to find an event as to perform it' (2002: 88). In the ASG finding the event, or discovering it, is a temporal experience, one of transferrable subjectivity and semiotic disturbance.

There are two events happening when the page is loaded. These, in turn, are the text of the code and the text of the screen. In digital poetics we understand that '[e]verything happening is subject to the grammar and the politics of code... [w] hat we see is the "Surface" of the code - [its] materialisation as text, sound, image and action on the screen' (Simanowski 2010: 137-139). The sub-textual element (the code) is read by the computer and the JavaScript event is initiated, and this generates the sur-textual event score (the screen). The JavaScript event is singular, only occurring once, the repetition of rewriting by reorganizing that happens on-screen is automatic and occurs every 4.5 seconds. This timeframe is specific in that it allows the viewer to read the score twice in their mind or once aloud before the next text replaces it. The process of looking at the screen, the altering texts and shifting layout is not dissimilar to watching a video or a sequence of images on a slide machine. As Giselle Beiguelman posits in 'The book after the book' (1997), 'The internet is no more than a big text. On the front, at the screen, text reveals itself as image' (Beiguelman in Schaffner 2010: 184). Anna Dezeuze offers a similar idea for the event score, stating that often

\footnotetext{
${ }^{1}$ http://nickm.com/poems/taroko_gorge.html. Another of Nick Montfort's computational poems, 'Lede' provided the basis of the r.nde used in the Ar.tinn Sronre Generator - IIsed with nermissinn
} 
Nathan Walker 'Permutation and Randomness in the Action Score Generator' 2014 '[t]he visuality... would predominate over their performative dimensions, encouraging the reader to look at them rather than using them as scores for performance' (Dezeuze 2002: 86) and this is the case for the ASG. Users are transformed into viewers and presented with an interface of altering textsimages, which I am calling action scores. The actions occurring are multiple and shift between textual, coded and conceptual spaces. Their combinational behaviour is not predetermined but random within the constraints of the textnodes. The action of replacing one text with another and the progression of texts is self-destructive as there is no way to return to a previous text. The generator moves in only one direction.

The viewer observes writing taking place within the computer, a writing based upon modular formations of the six textual nodes that are both functional and poetic. The progression from one text to the next with equal time delays and equal number of words creates a rhythm in which we 'get into the work' by reading. Reading makes the event happen, both in JavaScript code and within the surface of coded scores. We read the action scores as instructions but also as poems. They have the poetic constraint of a fixed word-length structure so they also create a rhythm of within six and eight syllables each time they are read. The visual arrangement bears no relation to the metre of the reading of these words - however, I believe the viewer organizes the form into halves, into a kind of dum-de-dum/dum-de-dum, three words at a time.

The meanings of words transform too, giving the reader multiple options for verbs and nouns that are context dependent. We read 'erase at car' and interpret what that could mean, the grammatical logic becomes obsolete and a poetic dynamism takes place. We read 'erase' to mean 'remove', 'take out' or 'obscure'. It does not matter that these words are not the word on the screen but the paradoxic function of the code producing another code gives us permission to decode what appears until we are comfortable with the message. Time here is crucial as a viewer you begin to race through reading, there is not time enough to linger, you cannot go back or save them in anyway. Similarly for 'postcard outside toes' we substitute 'outside' to mean 'not on top of' or 'not under', we work out what 'outside' might mean in the context of the score and shift our understanding to make the score function grammatically. This shifting, similar to the use of the term in choreographic practice, is a movement along the same plain. We do not shift up or down but across, within the framework of contextual dependence.

In the ASG these kinds of circularity and overlap are a logic of the fragment, the modular form enables a communication of transferrable subjectivity whereby the meaning may be communicated by the code or by the message. We move away from content and towards events and view these texts-as-images of unfolding and collage. As with Fluxus Event Scores, the modular form enables a shift from 'singular abstraction to repeatable model' (Robinson 2009: 79), where the performance is no longer a one-off but a serial segment, a writing performing writing. 


\section{References}

Beiguelman, G. (1997), 'The book after the book', http://www.desvirtual.com/thebook/english/project.htm. Accessed 1 March 2014.

Dezeuze, A. (2002), 'Origins of the fluxus score: From indeterminacy to the "Do-lt-Yourself' artwork', Performance Research, 7:3, pp. 78-94.

Kotz, L. (2001), 'Post-Cagean aesthetics and the "Event" score', October, 95, pp. 54-89.

Robinson, J. (2009), 'From asbtraction to model: George Brecht's events and the conceptual turn in art of the 1960's', October, 127, Pp. 77-108.

Schaffner, A. K. (2010), 'From concrete to digital: The reconceptualization of poetic space', in J. Schäfer and P. Gendollo (eds), Beyond the Screen: Transformations of Literary Structures, Interfaces and Genres, Bielefeld: Transcript Verlag, pp .179-98.

Simanowski, R. (2010), 'Event and meaning: Reading interactive installation in the light of art history', in J. Schäfer and P. Gendollo (eds), Beyond the Screen: Transformations of Literary Structures, Interfaces and Genres, Bielefeld: Transcript Verlag, pp. 137-52.

Wardrip-Fruin, N. (2011), 'Digital media archaeology: Interpreting computational processes', in E. Huhtamo and J. Parikka (eds), Media Archaeology: Approaches, Applications, and Implications, Berkeley: University of California Press, pp. 302-22.

Weiner, L. (1968), 'Statements', New York City, NY: The L. Kellner Foundation, S. Siegelaub.

Williams, E. ([196?] 1967), 'Cellar song for five voices', in E. Williams (ed.), An Anthology of Concrete Poetry, New York: Edition Hansjörg Mayer, Stuttgart, and Something Else Press, n.p. (question marked date in original publication).

\section{Acknowledgements}

Thanks to notes and encouragement from J. R. Carpenter and generous communication from Nick Montfort.

\section{Contributor details}

Nathan Walker is an artist, curator and writer. His work and research investigates writing and speaking in performance. He is interested in digital, conceptual and durational writing practices. His artworks exist as live performances, bookworks, online projects, sound poetry and video. Alongside artist Victoria Gray he is co-director of Oui Performance an arts organization committed to developing the practice, discourse and education of performance art in the United Kingdom. Nathan is currently Senior Lecturer in Performance at York St John University. 